Gestión y Estrategia

Gestão e Estratégia

Management and Strategy

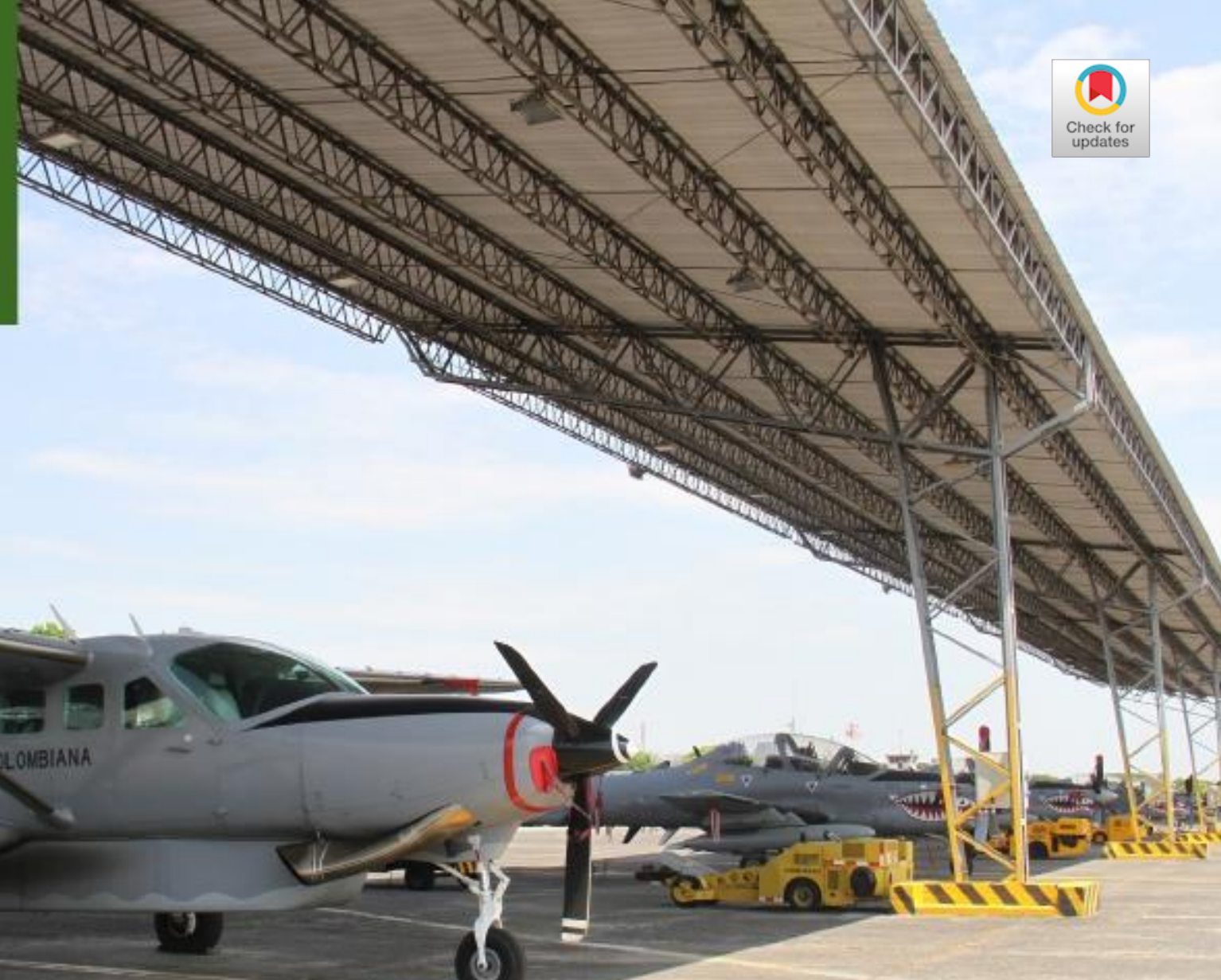

\title{
LAS NIIF: UNA FORMA DE EDUCAR A LOS GERENTES EN LA GESTIÓN DE LA PYMES ${ }^{1}$
}

AS NIIF: UMA MANEIRA DE EDUCAR A OS GERENTES NA GESTÃO DAS PME²

The Ifrs: A Way Of Educating Managers In The Management Of Smes ${ }^{3}$

Santiago García Carvaja ${ }^{4}$, Robinson Dueñas Casallas ${ }^{5}$, Henry Acuña Barrantes ${ }^{6}$ Universidad La Gran Colombia / Universidad Militar Nueva Granada

\section{CIENCIA Y PODER AÉREO}

ISSN 1909-7050 / E- ISSN 2389-2468 / Volumen 11/ Enero-diciembre de 2016/ Colombia/ Pp. 122-130 Recibido: 30/03/2016

Aprobado evaluador interno: 30/06/2016

Aprobado evaluador externo: 08/08/2016

Doi: http://dx.doi.org/10.18667/cienciaypoderaereo.528 
Para citar este artículo:

García, S., Dueñas, R, Acuña, H. (2016). Las NIIF: una forma de educar a los gerentes en la gestión de la PYMES. Ciencia y Poder Aéreo, 11 (1), pp-pp.

Doi: http://dx.doi.org/10.18667/cienciaypoderaereo.528

${ }^{1}$ Artículo de reflexión, derivado del proyecto de investigación DIS-1812, titulado "Cuadro de Mando Integrado NIIF para Pymes". Financiado por la Universidad Militar Nueva Granada (UMNG) y la Universidad la Gran Colombia (UGC).

${ }^{2}$ Artigo de reflexão derivado do projeto de pesquisa DIS1812, titulado "Tabela de Mando Integrado NIIF para PMEs". Financiado pela la Universidade Militar Nueva Granada (UMNG) e a Universidade La Gran Colombia (UGC).

${ }^{3}$ Reflection article derived from de research project DIS1812, titled "Integrated Control Panel IFRS for SMEs". Funded by the Military University of Nueva Granada (UMNG) and the Gran Colombia University (UGC).

${ }^{4}$ Docente Universidad La Gran Colombia UGC; Maestría, Administración de Empresas, Southern New Hampshire University. Estados Unidos. Experiencia en Mercadeo Masivo, Periodismo e investigación de Mercados. Actualmente se desempeña como docente investigador de la Universidad La Gran Colombia.santiago.garcia@ugc.edu.co

${ }^{5}$ Docente investigador de la Universidad Militar Nueva Granada, Magíster en Relaciones Internacionales. Correo electrónico:

${ }^{6}$ Docente-Investigador de la Escuela Española de Negocios Internacionales, Máster en negocios internacionales, comercio exterior, Global Marketing e internacionalización- MIBE, Doctorando en Negocios Internacionales - DIB de la EENI. Correo electrónico: hacuna@reingex.com
Resumen: este artículo explora el impacto de las Normas Internacionales de Información Financiera - NIIF sobre las Pymes en Colombia, y en las estrategias que todo gerente de empresa que lidera una empresa debe tener para el correcto manejo contable y financiero, con respecto a la entrada en vigencia de la nueva normatividad internacional. El estudio investigativo fue realizado bajo el modelo cualitativo y el enfoque hermenéutico. Se utilizó el método documental y descriptivo. Uno de los resultados que se evidenciaron fue la prioridad en los contadores en forjar la cultura en el uso de las NIIF, actividad que se debe extender hacia los gerentes de cualquier Pyme. En suma, esta es una labor conjunta entre Gobierno Nacional, Supervisores, Revisores Fiscales y Contadores, entre otros, porque se hace indispensable que la dirección de la Pyme en cabeza de este líder, debe buscar desde ahora involucrarse más con el área contable, dado que el no realizarlo desde el inicio, estaría forzado él y la empresa a cometer decisiones con posibles costos que pudieron evitarse.

Palabras clave:estrategia; gerente; gestión; NIIF; Pymes.

Resumo: essa pesquisa analisa o impacto das normas internacionais de informação financeira NIIF sobre as PMEs na Colômbia e nas estratégias que todo gerente que tem a liderança duma empresa deve ter para o manejo certo contável e financeiro, respeito à entrada em vigência da nova normatividade internacional. O estudo investigativo foi feito sob o modelo qualitativo e o foco hermenêutico. Usou-se o método documental e descritivo. Um dos resultados que se evidenciaram, foi a prioridade nos contadores para estimular a cultura no uso das NIIF, atividade que deve ser extensa aos gerentes de uma PME qualquer. Em resumo, essa e um labor conjunto entre o Governo Nacional, Supervisores, Revisores Fiscais e Contadores, entre outros, porque e indispensável que a direção da PME ao mandato daquele líder, deve procurar desde agora se envolver mais com a área contável, já que não faze-lo desde o inicio forçaria tanto ele quanto a empresa para tomar decisões com custos que poderiam ter sido evitados.

Palavras-chave: estratégia; gerente; gestão; NIIF; PME:

Abstract: This article explores the impact of the International Financial Reporting Standards IFRS on SMEs in Colombia and in the strategies that every company manager who leads a company must have for the correct accounting and financial management, with respect to the entry into force of the new international regulations. The research study was carried out under the qualitative model and the hermeneutical approach. The documentary and descriptive method was used. One of the results that was evidenced was the priority in the accountants in forjing the culture in the use of IFRS, an activity that must be extended towards the managers of any SME. In short, this is a joint effort between the National Government, Supervisors, Tax Reviewers and Accountants, among others, because it is imperative that the SME leadership at the head of this leader should look from now on to get involved more with the accounting area, since not doing it from the beginning, the company and him would be forced to make decitions with posible costs that could have been avoided.

Key Words: IFRS; Manager; Management; SMEs; Strategy. 


\section{"Es responsabilidad de los administradores involucrarse y conocer el alcance del cambio normativo que afectará a los negocios y entidades que gestionan". Articulo 19 decreto 2649/93}

\section{Introducción}

La sigla NIIF es un término ignorado para alguna población, pero para los grandes y pequeños empresarios se ha transformado en un tema imprescindible de consulta. Esta abreviatura significa "Normas Internacionales de Información Financiera" y desde hace un poco más de dos años, los patronos tienen la obligación de seguir los lineamientos contables establecidos por las autoridades nacionales de cada país. Se tiene la idea de que este tema le atañe exclusivamente al área financiera y a los profesionales de contabilidad de las empresas, lo cual no debe ser así porque el escenario debe involucrar a la Alta Gerencia de cada organización por pequeña que esta sea.

Según Ocampo \& Astudillo Villegas (2014) el interés por la entrada en vigor de las NIIF en Colombia empieza a tener espacios desde diferentes dimensiones, en la medida en que se considera un reto de singular importancia dar una respuesta acertada a las interpelaciones actuales acerca a la normatividad internacional contable.

Por lo anterior, se presentarán los principales retos gerenciales bajo criterios estratégicos y organizacionales que genera su implementación en las pymes colombianas

Como ya se mencionó, las NIIF son agrupaciones de normas con enfoque económico que pretenden crear una estructura uniforme para el manejo de la información financiera y contabilidad de las empresas, y se espera que sean, desde ahora, el lenguaje financiero universal. Las NIIF o IFRS "International Financial Reporting Standard", por sus siglas en inglés, son principios contables que apoyarán a Colombia y demás países de la región a insertarse de forma exitosa en un mundo globalizado que ya las implementan, para que empresarios y grupos de interés puedan tomar decisiones financieras de manera más acertada e informada. Desde el año 2010 más de 120 países permiten y requieren el uso de las NIIF; por eso se debe cerrar la brecha con el resto del mundo, a través de la implementación y convergencia.

Las normas NIIF reconocen a las pymes su aceptación contable en el marco legal internacional, lo que les permitirá incursionar en mercados no explorados y calificará positivamente los estándares de producción y de calidad, permitiendo ser empresas más rentables, estables en el tiempo y con márgenes de desarrollo y utilidad para los socios y/o accionistas.

En este documento se realizó un análisis del funcionamiento de las NIIF en las pymes, realizando observaciones del papel de la dirección de cada compañía, en especial del rol de los "Gerentes" en la identificación de la gestión más adecuada para la identificación de sus fortalezas y debilidades dentro de la empresa. Lo cual ayudará a diseñar estrategias gerenciales que permitan encaminar a las organizaciones a un lenguaje financiero común, con beneficios económicos y de rentabilidad; pero el reto de estos directivos está en resolver la siguiente pregunta ¿cómo se deben acomodar las áreas de la empresa a los diferentes cambios para la ejecución de las NIIF?

\section{Las Pymes como objetivos hacia las NIIF}

Acoger un lenguaje contable y financiero internacional que le permita a cualquier pymes realizar transacciones a nivel mundial o local con empresas que se encuentren en el mismo estándar de la Norma Internacional de Información Financiera.

Dar un apoyo y visión a los gerentes para realizar contratos en el horizonte nacional e internacional, con empresas que posean la estandarización de NIIF.

Conseguir resultados para la toma de decisiones fundamentados en la situación financiera de la Pyme, por medio del análisis comparativo entre las de su mismo nivel.

Normalizar procesos contables, administrativos y financieros, lo que permite equiparar los hechos financieros reales para realizar la implementación, capacitación y adaptación de las normas financieras.

E impedir sanciones económicas por parte de los organismos reguladores y de control que están controlando la implementación de las NIIF.

\section{Revisión literaria}

Dentro de la bibliografía para adoptar las NIIF en las pymes, sobresalen los conceptos de la implementación de las Normas Internacionales de Información Financiera para pequeñas y medianas entidades, y se describen los esquemas que le corresponde adoptar la dirección de las pymes, asimilados por las teorías de la administración.

Según el doctor Frederick Winslow Taylor, progenitor o creador de la administración científica, exponía que un paradigma en la administración (Hamel, 2008) es una re- 
Tabla 1.

Clasificación según tipo de empresa dor comprometido con cualquier tipo de establecimiento o empresa: una revolución mental completa de parte de esos hombres con respecto a sus deberes laborales, a sus compañeros y a sus empleadores. Implica también una revolución mental igualmente completa de parte de quienes están del lado de la gerencia: el capataz, el superintendente, el propietario del negocio, la junta directiva. La revolución mental completa con respecto a sus deberes para con sus asociados de la gerencia, sus trabajadores y sus problemas de todos los días. Sin esta revolución mental completa de parte y parte, la administración científica no existe.

A la vez, la ventaja competitiva continua se obtiene cuando la Pyme consigue estos resultados visibles en varios años (Hill, 2004), afirmando que la aptitud como ventaja competitiva es un condición de la organización, que muestra su capacidad operativa, permitiendo satisfacer las insuficiencias de sus clientes y la identificación de la competencia en el mercado. La competitividad es la búsqueda sostenible determinada por la permanencia (Bejarano, 1995) encaminada hacia los mercados (Roldan, 2004) y con la existencias de varios actores, dentro de los cuales se acentúan en el sector productivo, los clientes, el gobierno, y los clientes o usuarios (Bernal, 1995).

Para el Consejo de Normas Internacionales de Contabilidad (2009):

Las NIIF están diseñadas para ser aplicadas en los estados financieros con propósito de información general, así como en otra información financiera, de todas las entidades con ánimo de lucro. Los estados financieros con propósito de información general se dirigen a la satisfacción de las necesidades comunes de información de un amplio espectro de usuarios, por ejemplo accionistas, acreedores, empleados y público en general. El objetivo de los estados financieros es suministrar información sobre la situación financiera, el rendimiento y los flujos de efectivo de una entidad, que sea útil para esos usuarios al tomar decisiones económicas (p.11).

\section{Las Micro, pequeñas y medianas empresas en Colombia}

Con relación a La Ley 590 del 2000, la cual promueve el desarrollo de la Micro, Pequeña y Mediana empresa en Colombia, se encasillan en: Microempresa: personal no superior a 10 trabajadores. Activos totales inferiores a 501 salarios mínimos mensuales legales vigentes; Pequeña Empresa: personal entre 11 y 50 trabajadores. Activos totales mayores a 501 y menores a 5.001 salarios mínimos men-

\begin{tabular}{cc}
$\begin{array}{c}\text { Planta } \\
\text { de versonal }\end{array}$ & $\begin{array}{c}\text { Actives totalos on ealarios minimos } \\
\text { mensuales vioentes }\end{array}$ \\
\hline $51-200$ & $5.001-15.000$ \\
$11-60$ & $601-6.000$ \\
Hasta 10 & Interior a 500
\end{tabular}

Fuente: Ley 905 de 2004. Gobierno Nacional, República de Colombia.

suales legales vigentes; Mediana: personal entre 51 y 200 trabajadores. Activos totales entre 5.001 y 15.000 salarios mínimos mensuales legales vigentes.

En Colombia, según lo manifiesta Mondragón (2011), las micro, pequeñas y medianas empresas agrupan cerca del $95 \%$ de las pymes nacionales, en donde su participación se establece en un $30 \%$ del total de la producción, "aportan un poco más del $70 \%$ del empleo, remiten un poco más del $30 \%$ de las exportaciones y generan alrededor del $50 \%$ de los salarios. Así mismo, contribuyen al $41 \%$ del PIB nacional" (p. 12). A su vez, indica Vélez (2009) referente a las empresas "las Pymes se han consolidado como foco de desarrollo y elemento clave para el crecimiento económico no solo porque configuran un alto porcentaje del tejido empresarial colombiano, sino por su aporte al desarrollo de la economía del país y en la disminución de la pobreza" (p.1).

Es así que la aportación de las pymes en la economía colombiana del $100 \%$ de estas empresas se sitúa en el sector de servicios, con el 38\%. En este porcentaje se imparten las siguientes actividades: hoteles y restaurantes, informática, asesoramiento, publicidad, actividades de arquitectura. En el sector Industria a la par corresponde al $38 \%$ y se localizan pymes dedicadas a la manufactura de minerales no metálicos, muebles, alimentos y bebidas, prendas de vestir, productos de caucho y plástico, otras industrias manufactureras, marroquinería, productos metálicos, cuero calzado, sustancias y productos químicos, actividades de edición e impresión, maquinaria y equipo. En el sector comercio las pymes constituyen el $24 \%$, y se acentúan las dedicadas a alimentos y bebidas, productos farmacéuticos de perfumería y de tocador, artículos de uso doméstico, y ferretería cerrajería.

En el año 2014, la situación económica en general en el segundo semestre bajó con respecto a lo comparado en el año inmediatamente anterior, estos datos permiten observar la participación en los sectores de economía de las pymes y cómo los cambios en el sector macroeconómico, 
microeconómico, financiero, llegan a afectar el crecimiento y la rentabilidad de una empresa que se encuentra en el sector de clasificación como Pyme (Acopi, 2014).

La contribución de las pymes en las exportaciones evidenció el mayor crecimiento como exportadoras, y las grandes empresas tuvieron un menor crecimiento, las exportaciones en el 2001 de las pymes crecieron 10,2\% USD, y continuaron creciendo en esa vigencia (Pymes en Colombia, 2015).

\section{La NIIF, las PYMES y su implementación}

Mediante la Ley 1314 de 2009 en Colombia se adoptan las NIIF para PYMES, cuyo objeto fue la disposición de un sistema único y homogéneo de alta calidad, comprensible y de forzosa observancia, de normas de contabilidad, de información financiera y de aseguramiento de la información; como también el rol del Estado colombiano a través de la Contaduría General de la Nación, el Ministerio de Hacienda y Crédito Público, el Ministerio de Industria y Turismo y la DIAN; estos entes rectores, en conjunto, expiden normas, principios, interpretaciones y guías de contabilidad financiera y de fortalecimiento de la información, con el fin de formalizar la presentación ante el Consejo Técnico de la Contaduría Pública, quien es el organismo designado para la normalización y quien le corresponderá implementar las NIIF (IFRS), como técnica para la gestión de la contabilidad y de la información financiera en las empresas pymes.

En el 2008 los países que integran el grupo G20 $0^{1}$ reconocieron la importancia de las NIIF y mostraron el beneficio de organizar las normas contables a estándares mundiales, primordialmente en momentos de crisis; de este modo, dialogaron lo apremiante para robustecer la contabilidad con medidas inmediatas y a mediano plazo. Además, solicitaron a los organismos trabajar de manera inmediata en la elaboración de reglas globales únicas, de alta calidad e invitaron a reguladores, supervisores y emisores de pautas contables a trabajar mancomunadamente. En suma, se pidió al sector privado amparar esta normatividad para asegurar su implementación.

Es así, que numerosos países resolvieron desde el mismo instante orientar sus sistemas contables con las NIIF, con reuniones continuas sobre la forma en que se convendría dar ese proceso. Al respecto, Otal Franco afirmó que el asunto ha sido algo controvertido en varias regiones, puesto que involucra asuntos políticos como técnicos:

\footnotetext{
${ }^{1}$ Creado en 1999, es el grupo de las 20 principales economías (G20) incluye a países desarrollados y potencias emergentes.
}

En un país es vital definir si la convergencia es para grandes empresas que cotizan en los mercados de capitales o se refiere a pequeñas empresas. En mi opinión, es importante que las multinacionales que cotizan en varios mercados acojan las NIIF para la comparabilidad y transparencia (FCE-CIDb, 2015)

Se destaca que la implementación de las NIIF es un reto tanto para las empresas como para los profesionales, debido a que la contabilidad se realiza con el principio de entrega de obligaciones para la información tributaria. Desde allí nace el desafío, el cambio en el paradigma de la práctica contable, y en los procesos de las empresas que modifican y se transforman en la preparación y presentación de los estados contables.

A nivel nacional, la Asociación Colombiana de Medianas y Pequeñas Industrias (ACOPI), señala que solo el $5 \%$ de las pymes se desenvuelve en el mercado externo; las 95\% restantes maniobran dentro del país. Comúnmente las pymes no acuden a los mercados financieros para obtener recursos por lo que muchas de ellas cuestionan que el Estado les demande implementar la Norma.

\section{Breve reseña jurídica}

Con el Decreto 2784 de 2012 del Consejo Técnico de la Contaduría, (Tabla 2.) el cual reglamenta la Ley 1314 de 2009 se establece el régimen normativo para los preparadores de información financiera. Si bien, el año de adopción plena de las NIIF es el 2014 para plenas y el 2015 para pymes, en el caso de Colombia (Clarke, 2000) inició desde 2013 el proceso de adopción, lo cual implica la preparación, implementación y adopción de estos estándares internacionales. Con fecha 27 de diciembre de 2013 el Gobierno Nacional emitió los Decretos 3019, 3022, 3023 y 3024 referentes al proceso de adopción de las NIIF en el territorio nacional.

\section{Decretos relacionados con la NIIF en Colombia}

- Decreto Efecto 3019 / 2013 modifica el marco técnico normativo de información financiera para microempresas.

- Decreto 3022 / 2013 reglamenta la Ley 1314 sobre el marco técnico normativo para los preparadores de información financiera.

- Decreto 3023 / 2013 modifica parcialmente el marco técnico normativo de información financiera para los preparadores de la información financiera que conforman el Grupo 1, contenido en anexo del Decreto 2784 de 2012. 3024 / 2013 Modifica el Decreto 2784 de 2012. 
Tabla 2.

Decretos NIIF en Colombia

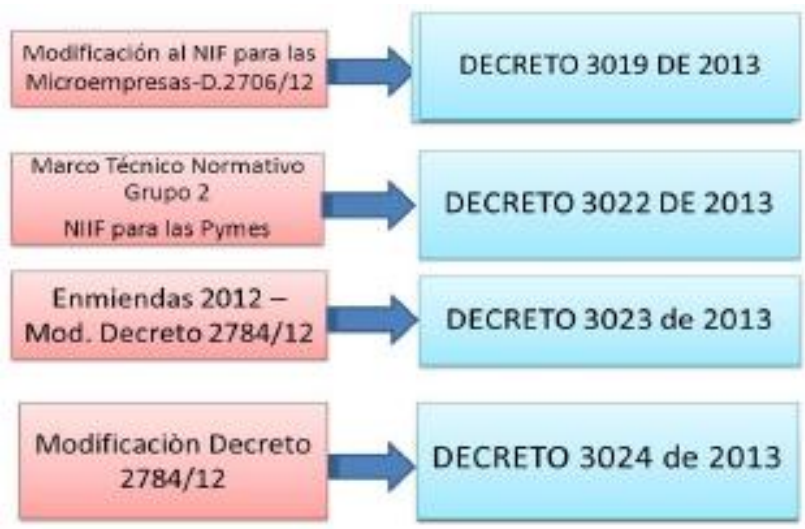

Fuente: elaboración propia.

De otra parte, debido a que el Decreto 2649 de 1993 no ha sufrido modificación en su trasfondo, en el medio se alzan voces argumentando que se solicitan adecuaciones, porque el mercado interno y externo lo demandan.

\section{Metodología}

El estudio investigativo fue realizado bajo el modelo cualitativo y el enfoque hermenéutico. Se utilizó el método documental y descriptivo investigativo; el primero, por la consulta realizada a diferentes documentos científicos en internet; y el segundo, porque de la información encontrada en la web se extrajo, describió e interpretó lo más trascendente de determinados conceptos, experiencias y aplicabilidad de la alta gerencia y sus áreas responsables.

En cuanto a las fuentes secundarias, se adelantó la búsqueda y clasificación ordenada en torno al objeto de conocimiento con el fin de que este tipo de fuentes nutrieran el trabajo de investigación desde diferentes puntos de vista y concepciones.

Retos y alternativas gerenciales en la implementación de las NIIF. En el actual modelo colombiano, resulta incuestionable que la implementación de las NIIF en el país soporta diversos retos para el área administrativa, juntas directivas, etc., pero en especial en la toma de decisión de los gerentes de las pymes. Es por ello que la implementación de la Norma, según los expertos consultados, se encuentra permeada en la actualidad por dos articulaciones que se suman a lo observado anteriormente:

A nivel gerencial y administrativo, las pymes no se han involucrado lo suficiente en la adopción de las NIIF, e inclusive aun la desconocen.
La responsabilidad de la correspondiente adopción se ha dejado solamente en cabeza de los contadores públicos que prestan sus servicios a las pymes.

Capacitación. Sin duda alguna, el proceso de implementación de las NIIF en las micro, pequeñas y medianas empresas colombianas tiene que pasar por períodos de capacitación, las mismas que deben proveerse a todos los colaboradores involucrados en el proceso de manera directa e indirecta; este proceso se podría dar por el mismo personal profesional en las áreas contables y financieras de una pyme, y, así, desplegar este tipo de capacitación a sus compañeros; asimismo, como también acudir a terceros especializados en la materia, quienes podrían, incluso, certificar los procesos.

Dada la densidad de los retos gerenciales en cuestión, es posible que también se requiera implementar acciones concernientes a una mayor formación del talento humano en cuanto a NIIF en las pymes colombianas, diferenciando la formación de la mera capacitación, como lo indica Gesycal, (2010), (...) el conjunto de acciones propuestas para optimizar las capacidades de los trabajadores en las empresas, tratando de constituir un equilibrio entre las aptitudes de los demás empleados y los requerimientos de su quehacer profesional.

Por lo anterior, se requiere no solamente incrementar las capacitaciones al interior de las pymes colombianas sino también fortalecer los procesos de formación, pues allí es donde en realidad se pueden producir los cambios de fondo. Autores como Uribe (2009), afirman que "por lo menos la mitad del pensum (universitario de programas académicos) deberá ser renovado, es decir, como mínimo el $50 \%$ de nuestra carrera deberá ser re-estudiado"(p.1). De la afirmación anterior, no importa tanto el porcentaje, dado que este podría ser mayor o menor, pero si la indicación de que estamos ante un cambio profundo en la formación contable. Se requiere prepararlas para adoptar una nueva cultura contable y financiera.

La dirección de las Pyme y el gerente. Naturalmente, expresaba Elliott Jaques (2002) en relación con el rol de los gerentes, que el liderazgo es "la capacidad de desarrollar planes estratégicos sólidos que permitan alcanzar las metas que el directorio o el propietario han fijado para la compañía" (p.13). Lo anterior, no puede imaginar en las pymes colombianas el alcance de un compromiso tan serio, como la implementación de las NIIF, sin el irrestricto liderazgo y compromiso de las cabezas de quienes las orientan en sus decisiones. 
Por ello, puede se certificar que todo el proceso en mención debe estar liderado por los gerentes a cargo en cada Pyme, apoyado y organizado por los correspondientes profesionales contables y financieros, pero igualmente intervenido con todos aquellos colaboradores que, de acuerdo con sus cargos y áreas funcionales, deban contribuir al entendimiento y la adopción de las NIIF al interior de las pymes.

Es por ello, que el gerente como cabeza de la Pyme es la persona encargada por la dirección de dirigir la organización y tomar las decisiones más apropiadas teniendo siempre en cuenta el personal a cargo, ya que las personas son el factor fundamental en cualquier organización, brindarles la capacitación, los descansos y lo necesario para que se sientan a gusto, motivados y cómodos con el trabajo que conlleva la implementación de las NIIF. A su vez, el contador quien lleva el procedimiento, es el comisionado de registrar los hechos y transacciones económicas dentro de la organización, plasmando así las normas y reglas propuestas para este fin. Las normas internacionales demandan por tanto a todos los profesionales, conocer, estudiar, determinar su contenido, impacto, sus procesos y procedimientos para el manejo de la información.

Áreas que implementan la NIIF. Para que todo lo anterior se realice de la manera más idónea y adecuada, la alta dirección debe garantizarle al gerente que esta pyme tenga el respaldo y las áreas que apoyen la gestión y las orientaciones del líder de cada empresa; por lo anterior, se debe tener fortalecida algunas de las áreas que se relacionan a continuación:

Departamento de sistemas o afín. El cual debe buscar las maneras más adecuadas para que la información financiera pueda ser analizada y comprendida por la alta dirección en cabeza de los gerentes, contadores y usuarios externos. Una de sus labores sería en constituir datos automatizados que cumplan con los formatos de estados financieros establecidos por la norma.

Recursos Humanos. Debe fundamentalmente, planear estímulos para el profesional contable que sea experto en NIIF, para retener su capacidad y experiencia en beneficio de la empresa, ya que su conocimiento será requerido por las demás pymes.

Control Interno. Esta asume los controles de prevención y descubrimiento de estafa. Con la implementación de las NIIF, habrá la posibilidad de maniobrar los estados financieros.

Jurídica. Manejará el control de los contratos suscritos, caso contrario, no se podrá tener certeza de si los estados financieros están completos o si recogen todas las actuaciones contractuales de la pyme.

Finalmente, entre otras áreas también se debe tener presente, el área de contabilidad, dado que allí se asume en gran medida el proceso de implementación de la NIIF, como conocedores integrales de la normatividad, deberán estar plenamente capacitados y motivados en su ejecución.

Por todo lo anterior, Janica \& Piñero, (2008) señalan que así, la contabilidad organizada bajo esquemas internacionales mostrará estados financieros con información de calidad, comparable y coherente con los requerimientos de los usuarios, que se convierte en la obtención de ventaja competitiva en el momento de efectuar compensaciones económicas en los escenarios nacionales e internacionales.

Sustentan los estudiosos y consultores del tema, que las implementaciones de las NIIF con cualquier Norma debe ser un proceso estratégico que ponen en acción planes que se deben cumplir en las empresas. Con fundamento en lo anterior, resulta posible listar de manera preliminar y puntual los principales retos que genera la implementación de las NIIF en las pymes colombianas, asumiéndola no solamente como algo de carácter contable financiero, sino como un propósito de carácter estratégico para la organización de cualquier pyme:

- Necesidades de capacitación y de formación al interior de las pymes, en tránsito hacia una nueva cultura;

- requerimientos de liderazgo, de trabajo en equipo y cronograma de adopción;

- adopción y adaptación de las NIIF al ambiente contable y financiero;

- asimilación estructural e integral por parte de las pymes de las NIIF;

- valoración de las incidencias en los niveles contable y financiero de las NIIF en las pymes;

- necesidades de retroalimentación y de investigación interna de las pymes sobre las NIIF.

La meta central de la capacitación es proveer a los colaboradores de las habilidades y los conocimientos que mejoren su aptitud y sus prácticas en aquello que pueda enfocarse a diversos fines organizacionales.

\section{Resultados}

A lo largo de esta investigación, se logra reconocer lo importante y complejo que es la implementación de las NIIF, dado que se han convertido en uno de los grandes 
retos organizacionales para las pymes, en cuanto a la preparación, capacitación, adecuación y flexibilización de sus procesos estratégicos, operativos y misionales, para la conversión hacia este modelo mundial.

Las asociaciones, gremios y las mismas instituciones de educación superior, particularmente sus facultades de ciencias económicas y sus programas de contaduría, economía y administración deben ser los entes que deben vincularse definitivamente a esta transformación de las NIIF, atendiendo las necesidades de investigación y de retroalimentación que se generen en el medio empresarial de las pymes; y sobre las universidades, estas deben aumentar el número de programas de capacitación y formación en torno a las normas; dado que los lideres o gerentes en la actualidad según lo observado adolecen de capacitaciones sobre este tema.

De acuerdo con los objetivos específicos planteados, los autores consignan a continuación, y de manera puntual, las siguientes conclusiones:

\section{Conclusiones y discusiones}

La alta dirección, en cabeza del gerente, debe buscar desde ahora involucrarse más con el área contable y financiera, pues el no realizarlo desde el inicio condenará al fracaso al gerente y líder y a la misma empresa, y le acarreará posibles costos que pudieron haberse evitado para la pyme; por ello, a manera de ejemplo, no basta en tener una reunión al mes para revisar el cierre, se debe incrementar la comunicación con contabilidad y finanzas, se debe "romper" el paradigma de la información "sensible" que muchas veces no la conoce el contador, ya que él debe estar también al tanto de todo.

Las Normas Internacionales de Información Financiera por ser esquemas internacionales cambiantes y dinámicos, se presume una actualización y capacitaciones permanente por parte de los integrantes responsables; no se trata de desplazar al contador en ningún instante; sí bien proceden nuevos retos para el gerente (administrador, contador, economista, ingeniero o profesional con experiencia). Esto no representa para él un rol diferente, más bien se acentúa, en especial por la mayor flexibilidad y apoyo para el área contable y financiera.

La certificación que simultáneamente con el contador realiza el representante legal no puede continuar siendo observada como un formalismo, sino como la realización de una conducta. Es indudable que la colectividad de los contadores tiene un enfoque más contable que financiero; sin embargo, las NIIF revisten este último, con lo cual se demandará de mediciones y valoraciones donde es fundamental la madurez de los gerentes de cada pyme.

Se conciben numerosos retos gerenciales bajo criterios estratégicos y organizacionales frente a la implementación de las NIIF en las pymes colombianas, lo que le da un carácter esencial a los mandos directivos no solamente para que asuman el liderazgo de los correspondientes procesos sino que deben utilizar todos sus potenciales de creatividad e innovación, para conducirlos y concretarlos de la manera más exitosa posible con su personal y con el dinamismo en la aplicación de la NIIF de la empresa.

A su vez las pymes, por lo estudiado de ellas en la mayoría de ciudades colombianas, cuentan con pocos recursos económicos para la implementación y procesos de transición hacia las NIIF, consecuentemente las gerencias de estas empresas deben propender por la maximización en la disminución de costos, esto se llevará a cabo siendo proactivo, preparando el proyecto sin perder un instante. La alta dirección debe ser consecuente de la obligatoriedad de la transición a la NIIF y de los beneficios de presentar sus estados financieros con base en estándares contables internacionales, ello proporcionará una puerta amplia a la demanda que puedan requerir los mercados nacionales e internacionales, y la posible disminución de costos para las pymes y, por lo tanto, una mayor cobertura interna o externa.

\section{Referencias}

Acopi (2014). Pymes en Colombia, Informe principales sectores/ clasificación Pymes. Recuperado de: http://acopi.org.co/ pymes.2014

Bejarano, J(a). (1995). La competitividad en el sector agropecuario. Cuadernos de Desarrollo Agrícola. Vol 1, no. 1, 46-56.

Bernal, C. E. (1995). Proyecto de Modernización de las PYMES. Gestión tecnológica. Bogotá: Servicio Nacional de Aprendizaje.

Castaño Ríos, Carlos; Zamarra Londoño, Julián; Correa García, Jaime (2014). Efectos financieros en una cooperativa colombiana por la implementación de estándares internacionales de información financiera para las PYME en su balance de apertura. Cuadernos de Contabilidad, 15 (38), pág. 427-458.

Clarke, A. (2000). Historia de la contabilidad en Colombia. 19231966: y Experiencias de un Contador Público. Bogotá, Colombia: Instituto Nacional de Contadores Públicos de Colombia.

Colombia (1993). Decreto reglamentario 2649 de 1993, por el cual se reglamenta la contabilidad en general y se expiden los principios o normas de contabilidad generalmente aceptados en Colombia. Diario Oficial, 41.156, 29. Obtenido de:http://www.alcaldiabogota.gov.co/sisjur/normas/Norma1.jsp?i=9863 
CIENCIA Y PODER AÉREO | Revista Científica de la Escuela de Postgrados de la Fuerza Aérea Colombiana | Vol. 11 | Enero - Diciembre de 2016

Colombia (2012). Decreto reglamentario 2706 de 2012, por el cual se reglamenta la Ley 1314 de 2009 sobre el marco técnico normativo de información financiera para las microempresas. Diario Oficial, 48.657. Obtenido de: http://www.alcaldiabogota.gov. co/sisjur/normas/Norma1.jsp?i=51148

Consejo de Normas Internacionales de Contabilidad (2009). Norma Internacional de Información Financiera para Pequeñas y Medianas Entidades (Niif Para Las Pymes) 1, 11. ISBN for complete publication (three parts): 978-1-907026-34-8

Decreto 2784 de 2012. (2012, diciembre 29). Diario Oficial No. 48.658. Bogotá, Colombia: Imprenta Nacional.

Decreto 2649 de 1993. (1993, diciembre 23). Diario Oficial No.41.156. Bogotá, Colombia: Imprenta Nacional.

Decreto 2784 de 2012. (2012, diciembre 29). Diario Oficial No. 48.658. Bogotá, Colombia: Imprenta Nacional.

Decreto 3019 de 2013. (2013, diciembre 27). Diario Oficial No. 49.016. Bogotá, Colombia: Imprenta Nacional.

Decreto 3022 de 2013. (2013, diciembre 27). Diario Oficial No. 49.016. Bogotá, Colombia: Imprenta Nacional.

Decreto 3023 de 2013. (2013, diciembre 27). Diario Oficial No. 49.016. Bogotá, Colombia: Imprenta Nacional.

Decreto 3024 de 2013. (2013, diciembre 27). Diario Oficial No. 49.016. Bogotá, Colombia: Imprenta Nacional.

FCE-CIDb. (13 de 10 de 2015). Centro de Investigaciones para el Desarrollo. Obtenido de Universidad Nacional de Colombia:

http://www.cid.unal.edu.co/cidnews/index.php/component/ content/ article/79-historial/2570-niif-empresas-contaduriafinanzas.html

GESYCAL (2010). ¿Qué es formación empresarial y para qué sirve? Recuperado de http://www.gesycal.com/que-es-formacionempresarial-para-que-sirve/

Janica, F. \& Piñeros, J. (2008). Usgaap Vs. Ifrs y Colgaap. Lo básico. Ernst \&Young Audit Ltda. Recuperado del sitio de internet http://www. globalcontable.com/archivosgenerales/seccione s/ifrs/comparativos/ey/colgaapbasico.pdf.

Jaques, E. (2002). Social power and the CEO: Leadership and trust in a sustainable free enterprise system. Westport, CT: Quorum. Cap. 13.

Hamel, G. (2008). El futuro de la Administración. Bogotá: Grupo editorial Norma.

Hill, W. y Jones, G.R. (2004). Administración estratégica, un enfoque integrado. México. D.F: $6^{\mathrm{a}}$ ed Macgraw- Hill.

Ley 1314 de 2009. (2009, julio 13). Diario Oficial No. 47.409. Bogotá, Colombia: Imprenta Nacional.

Mondragón, J. (2011). Innovación para la integración global de las Pymes. Pyme. La revista. Asociación de las Micro, Pequeñas y Medianas Empresas ACOPI, (25)
Ocampo \& Astudillo Villegas (2014). Retos y alternativas gerenciales en la implementación de las NICNIIF en las pymes colombianas. Magazín Empresarial, 10(26), 11-19.

PYMES en Colombia. (13 de 10 de 2015). Obtenido de Microempresas colombianas pequeña y mediana Acopi Expopyme Proexport: http://www.businesscol.com/empresarial/pymes/

Roldan. D \& Espinal, C. F. (2004) ¿Son posibles los acuerdos de competitividad en el sector agro productivo? Colección de documentos IICA, serie competitividad No. 3. Bogotá.

Vélez, M. (2009). Desarrollo de un micromundo orientado a soportar la Administración de crecimiento en pequeñas y medianas Empresas. Universidad Nacional de Colombia.

Zapata, G., \& Hernández, A. (2010). Sistema de incentivos y tipos básicos de trabajo en la organización bajo la perspectiva de la teoría de agencia. Pensamientoy gestión, N²9, pp. 56-86.

130 | Las NIIF: una forma de educar a los gerentes en la gestión de la pymes 